\title{
Estresse oxidativo em cães com doença periodontal: comparação dos biomarcadores plasmáticos e salivares
}

\author{
[Oxidative stress in dogs with periodontal disease: comparison of plasmatic and salivary biomarkers] \\ M.R. Silva, D. Matono, A.M. Bosco, L. Baptistiolli, R.B.P. Torrecilha, P.C. Ciarlini*
}

Universidade Estadual Júlio de Mesquita Filho - Araçatuba, SP

\begin{abstract}
RESUMO
A doença periodontal (DP) é a enfermidade inflamatória mais comum da cavidade oral dos cães. A quantificação de biomarcadores do plasma e da saliva tem sido utilizada para avaliar o estresse oxidativo sistêmico (EOS) e local (EOL) da DP humana. Na DP canina, os mecanismos do estresse oxidativo não estão bem caracterizados e estabelecidos. O objetivo do presente estudo foi investigar a hipótese de que o EOS ocorre na DP canina e de que a saliva pode ser utilizada para avaliar o EOL. Analisou-se, também, a hipótese de que a ativação do metabolismo oxidativo dos neutrófilos contribui para EOS na DP dos cães. Para tal, foram selecionados 20 cães adultos portadores de DP, agrupados de acordo com o grau de lesão: gengivite $(n=6)$, periodontites leve ( $n=8)$ e avançada $(n=6)$. O grupo controle foi composto pelos mesmos 20 cães, 30 dias após o tratamento periodontal. Para avaliar o metabolismo oxidativo dos neutrófilos circulantes foi quantificada a produção de superóxido pelo teste de redução do tetrazólio nitroazul (NBT). As concentrações de oxidante total (TOC) e de espécies reativas ao ácido tiobartbitúrico (TBARS) no plasma foram quantificadas para avaliar o EOS. Para a avaliação do estresse oxidativo local, foi quantificado o TOC salivar e a concentração dos principais antioxidantes da saliva (albumina, ácido úrico e bilirrubina total). O EOS na DP foi confirmado pelo aumento da produção de superóxido dos neutrófilos circulantes, TOC e TBARS plasmático. Foi possível quantificar todos os biomarcadores na saliva de cães, porém nenhum foi capaz de expressar o EOL da DP canina. Esta é uma das primeiras evidências de que o EOS ocorre em cães com DP e que a ativação do metabolismo oxidativo dos neutrófilos pode contribuir para desequilíbrio entre antioxidantes e oxidantes. Este estudo ressalta a importância da higiene bucal dos cães para a prevenção da DP e de lesões degenerativas crônicas de diversos tecidos causadas pelo EOS.
\end{abstract}

Palavras-chave: periodontite, gengivite, metabolismo oxidativo, superóxido, capacidade antioxidante

\begin{abstract}
Periodontal disease $(P D)$ is the most common inflammatory disease of the oral cavity of dogs. Quantitation of plasma and salivary biomarkers have been used to assess the systemic oxidative stress (SOS) and local (LOS) of human PD. In canine PD, oxidative stress mechanisms are not well characterized and established. Our objective was to investigate the hypothesis that SOS occurs in dog PD and saliva can be used to evaluate the LOS. We also investigated the hypothesis that the activation of neutrophil oxidative metabolism contributes to SOS in dog SD. For this purpose, 20 adult dogs were selected PD patients, grouped according to the degree of injury: gingivitis $(n=6)$, light periodontitis $(n=8)$ and advanced periodontitis $(n=6)$. The control group was composed of the same 20 dogs, 30 days after periodontal treatment. To assess oxidative metabolism of circulating neutrophils superoxide production was measured by test nitroblue tetrazolium reduction (NBT). The total oxidant concentrations (TOC) and reactive species to tiobartbitúrico acid (TBARS) in plasma were quantified to evaluate SOS. For the evaluation of local oxidative stress were quantified salivary TOC and concentration of the main antioxidant in saliva (albumin, uric acid, and total bilirubin). EOS in dogs with PD was confirmed by increased superoxide production of circulating neutrophils, TOC, and plasma TBARS. It was possible to
\end{abstract}

Recebido em 15 de junho de 2016

Aceito em 31 de janeiro de 2018

*Autor para correspondência (corresponding author)

E-mail: ciarlini@fmva.unesp.br 
quantify all the biomarkers in the saliva of dogs, but none was able to express the LOS canine PD. This is the first evidence that SOS occurs in dogs with PD and that activation of the oxidative metabolism of neutrophils may contribute to an imbalance between oxidants and antioxidants. This study highlights the importance of oral hygiene of dogs to prevent PD and chronic degenerative lesions of various tissues caused by SOS.

Keywords: periodontitis, gingivitis, oxidative metabolism, superoxide, antioxidant capacity

\section{INTRODUÇÃO}

A doença periodontal (DP) é uma enfermidade imuneinflamatória, caracterizada por ruptura do tecido conjuntivo, perda de ligação e reabsorção óssea alveolar. Sua fase inicial é evidenciada por inflamação da gengiva, dor, sangramento e halitose devido ao acúmulo de placa bacteriana nas superfícies dentárias (Thomas et al., 2014). Acredita-se que a lesão periodontal se amplifica quando as espécies reativas de oxigênio (ERO) superam a capacidade antioxidante da saliva (Konuganti et al., 2012). O neutrófilo é a célula mais abundante na resposta inicial aos microrganismos da placa bacteriana humana, sendo grande parte das ERO na cavidade bucal do homem derivada do superóxido gerado durante a ativação do metabolismo oxidativo dos neutrófilos, e exerce importante função de controlar o crescimento bacteriano (Bhansali et al., 2013).

O estresse oxidativo sistêmico na DP humana tem sido caracterizado pela maior capacidade de oxidantes totais (TOC - total oxidant capacity) no plasma (Wei et al., 2010), pelo aumento da peroxidação lipídica plasmática (Dalai et al., 2013), pelo aumento do metabolismo oxidativo dos neutrófilos (Bhansali et al., 2013) e pelo declínio da capacidade antioxidante total (TAC total antioxidant capacity) do plasma (Thomas et al., 2014). A saliva também possui importante atividade antibacteriana, antiviral e antifúngica (Schenkels et al., 1995). A capacidade antioxidante da saliva é considerada a primeira linha de defesa contra as ERO produzidas durante o processo de digestão dos alimentos e a DP (Battino et al., 2002).

Por ser de fácil obtenção e manter contato íntimo com as lesões bucais, a análise de marcadores de estresse oxidativo na saliva ganhou importância e passou a ser utilizada para melhor compreender os mecanismos envolvidos nas DP em humanos (Zimmermann e Wong, 2008). O ácido úrico constitui mais de $85 \%$ da atividade antioxidante total da saliva de indivíduos saudáveis, enquanto outros 5 a $10 \%$ dessa atividade são atribuidos à albumina, glutationa, transferrina, lactoferrina e ceruloplasmina (Moore et al., 1994). Especula-se que a TAC salivar pode não diminuir na DP humana devido ao aumento do fluido genvival clevicular, rico em antioxidante (Battino et al., 2002). O aumento da peroxidação lipídica da saliva (Miriscescu et al., 2014) e do TOC salivar (Wei et al., 2010) tem sido utilizado como um indicador de estresse oxidativo na DP humana.

Embora a DP acometa até $80 \%$ da população canina (Riggio et al., 2011), pouco se sabe sobre o estresse oxidativo causado pelas lesões periodontais nesta espécie. Há um relato de que existe uma correlação negativa entre o TAC sérico e o grau de inflamação gengival (Pavlica et al., 2004). Especula-se que a inflamação bacteriana no ambiente periodontal pode gerar um aumento da produção de ERO em tecidos adjacentes de cães (Pavlica et al., 2004).

O objetivo do presente trabalho foi investigar as hipóteses de que, na DP canina, ocorre estresse oxidativo sistêmico associado à ativação do metabolismo oxidativo dos neutrófilos e de que a saliva pode ser utilizada para avaliar o estresse oxidativo local.

\section{MATERIAL E MÉTODOS}

Foi realizado um estudo clínico controlado, de acordo com os princípios éticos em uso de animais do Comitê de Ética em Experimentação Animal da Universidade Estadual Paulista (Protocolo FOA-2013-01126).

Foram selecionados 20 cães adultos (2-12 anos) portadores de DP e sem outras alterações nos exames clínico e laboratorial (hemograma completo e perfil bioquímico plasmático). A classificação da DP foi a mesma adotada em estudos anteriores sobre o tema (Pavlica et al., 2004; Nemec et al., 2013), utilizando-se critérios clínicos preconizados (Santos et al., 2012). 
Conforme critérios de Nemec et al. (2013), os cães foram divididos em três grupos de DP (Tab. 1). O grupo 1 consistiu de apenas animais com gengivite; o grupo 2 (periodontite leve) foi constituído apenas de animais com até $25 \%$ dos dentes afetados; e o grupo 3 (peridontite avançada) constituiu-se de animais com mais de $25 \%$ dos dentes afetados com periodontite leve e avançada. O grupo controle (GC) para cada grupo de DP foi constituído pelos mesmos cães, 30 dias após o tratamento periodontal, todos sem alterações no exame físico, no hemograma e no perfil bioquímico.

O exame bucal foi feito com o animal anestesiado, antes do tratamento . Com o auxílio de uma sonda periodontal milimétrica (WilliamsGolgran $($ ), a profundidade de sondagem (PS) e o nível de inserção (NI) foram mensurados em três pontos na face vestibular de cada dente analisado (terceiro incisivo, caninos, quarto prémolares e primeiro molar maxilar e mandibular). Somente o sítio com bolsa mais profunda foi anotado. A PS foi determinada pela mensuração da distância entre a margem gengival livre até o limite apical do suco gengival. O NI foi mensurado pela distância entre a junção cemento-esmalte até o sulco gengival (Canakci et al., 2007).

O índice de inflamação gengival (IG) foi determinado para quantificar a severidade da gengivite, conforme critérios de Pavlica et al. (2004). A mensuração do índice de cálculo (IC) foi feita segundo Corrêa et al. (1998), sendo considerado o escore 0 equivalente à ausência de cálculo e o 3 relativo à presença de cálculo cobrindo todo o dente (Corrêa et al.,1998). Para determinar a frequência de sangramento gengival, foram considerados positivos apenas os casos em que os dentes sangraram até 15 segundos pós-sondagem (Canakci et al., 2007). Todas as mensurações odontológicas foram realizadas por um único profissional treinado, com formação em odontologia e medicina veterinária, e os dados registrados em um odontograma específico.

Posteriormente a jejum alimentar (oito horas) e hídrico (uma hora), a salivação foi obtida após estímulo olfatório e visual padronizado, quantidade e tempo, com uma única marca de petisco comercial para cães. A saliva foi obtida introduzindo-se rolinhos de algodão odontológicos absorventes (Soft plus ${ }^{\circledR}$ ) esterilizados, na superfície gengival vestibular e lingual, superior e inferior. Os rolinhos de algodão com saliva foram colocados em tubo de ensaio $(10 \mathrm{~mL})$ contendo, em seu interior, microtubos cônicos de polipropileno $(1,5 \mathrm{~mL})$ sem tampa e com o fundo vazado. Após 10 minutos de centrifugação (5000xg), a saliva filtrada foi aspirada e acondicionada em microtubo de polipropileno protegido da luz. Todas as análises laboratoriais da saliva foram realizadas imediatamente após sua obtenção.

Por punção da veia jugular, quatro mililitros de sangue foram coletados e transferidos para tubo contendo heparina sódica (Vacutainer plus plastic Heparin, Becton-Dickson, New Jersey, USA), do qual se obteve plasma para realização do perfil bioquímico e determinação dos marcadores de estresse oxidativo. O plasma foi armazenado a $-20^{\circ} \mathrm{C}$ e protegido da luz até o momento das análises (máximo dois meses). Para a realização do hemograma, meio mililitro de sangue total foi acondicionado em tubo plástico contendo anticoagulante, na proporção de 1,8mg EDTA-sódico/mL de sangue.

Foram excluídos do estudo animais soropositivos para leishmaniose visceral pelo método ELISA (Lima et al., 2003) ou tratados nas últimas 72 horas com qualquer medicação. Após a seleção dos cães com DP, eles foram medicados por sete dias com espiramicina (750.000UI) associada com metronidazol $(125 \mathrm{mg})$, sendo a primeira dose realizada três dias antes do tratamento periodontal.

Todos os cães foram induzidos à anestesia com propofol e mantidos em anestesia geral inalatória com isoflurano $1,5 \%$, a fim de se realizar o tratamento periodontal, conforme recomendações de Harvey e Emily (1993). A terapia foi realizada em uma única sessão e por um único profissional treinado. Para tal, foi utilizado ultrassom odontológico (Gnatus, Jet Sonic $\left.{ }^{\circledR}\right)$ e curetas (Perio Gracey Millennium - Goldran) para a remoção da placa bacteriana e do cálculo dentário sub e supragengival. Para o polimento e o alisamento da superfície dentária, foram utilizadas escovas de Robson (Micromotor Marathon M-3 Mighty®) e pasta profilática composta de pedra-pomes e gel fluoreto de sódio a $2 \%$. 
O hemograma completo foi determinado com auxílio de contador eletrônico de células sanguíneas (BC-2800 Vet, Mindray, China), sendo a contagem diferencial de leucócitos realizada em esfregaços sanguíneos corados com corante hematológico panótico rápido comercial (Instant-Prov, NEWPROV, Pinhais - PR).

Todas as análises bioquímicas plasmáticas foram realizadas em analisador bioquímico automatizado (BS 200, Mindray, China), previamente ajustado com calibrador comercial, controles níveis I e II (Biosystems, Barcelona, Spain). Mediante a utilização de conjunto de reativos comerciais (Biosystems, Barcelona, Spain), foi mensurada a concentração plasmática de ácido úrico pelo método enzimático (uricase/peroxidase); albumina pelo método do verde de bromocresol; ALT e AST pelo método enzimático UV (glutamato desidrogenase); bilirrubina total pelo método sulfanílico diazotado; colesterol pelo método enzimático (colesterol oxidase/peroxidase); creatinina pelo método cinético (picrato alcalino); proteína total plasmática pelo método do biureto; triglicerídeos pelo método do glicerol fosfato oxidase/peroxidase; e ureia pelo método enzimático UV (urease/glutamato desidrogenase). A TOC no plasma e na saliva foi determinada por meio da mensuração do ion férrico indicado pelo laranja de xilenol em meio ácido, conforme descrito por Erel (2005), e os resultados foram expressos em $\mu$ mol de peróxido de hidrogênio equivalente/L. Todas as reações bioquímicas foram processadas a $37^{\circ} \mathrm{C}$.

A peroxidação lipídica plasmática foi determinada pela quantificação das espécies reativas ao tiobarbitúrico (TBARS), com auxílio da leitora ELISA automática (Robonik, Elisa Plate Analyser, India) e absorbância 540nm, conforme Hunter et al. (1985). Para se avaliar o metabolismo oxidativo dos neutrófilos, foi quantificada a produção neutrofílica de superóxido pelo teste citoquímico de redução espontânea do NBT descrito por Bosco et al. (2012).

As variáveis foram testadas quanto à normalidade (teste de Kolmogorov-Smirnov) e homocedasticidade (teste Bartlett). Para se verificar o efeito da DP sobre o estresse oxidativo em relação ao sexo, a diferença entre os grupos foi determinada pelo teste MannWhitney. A fim de se avaliar a diferença entre plasma e saliva, foi utilizado o teste $\mathrm{t}$ pareado. Para se compararem as variáveis de acordo com o grau de lesão (gengivite, peridonite leve e avançada), foi empregado o teste ANOVA, com pós-teste de Tukey. Foram consideradas diferenças significativas entre os grupos quando $\mathrm{P}<0,05$. Todas as análises estatísticas foram realizadas com auxílio de um programa computacional estatístico (Graphpad Instat software 3.0).

\section{RESULTADOS}

Os cães do GC (Tab. 1) não apresentavam sangramento nem cálculos dentários, e os valores de profundidade de sondagem (PS), nível de inserção (NI) e índice de inflamação gengival (IG) estavam dentro da faixa de normalidade (Beard e Beard, 1989).

Tabela 1. Comparação de cães com doença periodontal e respectivos controles. Valores médios e desviospadrão da profundidade sondagem (PS) e nível de inserção (NI), medianas dos índices de inflamação gengival (IG)), índice de cálculo (IC) e porcentagem de sangramento

\begin{tabular}{|c|c|c|c|c|c|c|}
\hline & $\begin{array}{l}\text { Gengivite } \\
\quad(n=6)\end{array}$ & $\begin{array}{l}\text { Controle } \\
(\mathrm{n}=6)\end{array}$ & $\begin{array}{l}\text { Periodontite leve } \\
(\mathrm{n}=8)\end{array}$ & $\begin{array}{c}\text { Controle } \\
(n=8)\end{array}$ & $\begin{array}{c}\text { Periodontite } \\
\text { avançada }(n=6)\end{array}$ & $\begin{array}{c}\text { Controle } \\
\quad(n=6)\end{array}$ \\
\hline Peso (kg) & \multicolumn{2}{|c|}{$6,39 \pm 3,49$} & \multicolumn{2}{|c|}{$15,16 \pm 15,46$} & \multicolumn{2}{|c|}{$4,52 \pm 2,62$} \\
\hline$\pi / q$ & \multicolumn{2}{|c|}{$3 / 3$} & \multicolumn{2}{|l|}{$4 / 4$} & \multicolumn{2}{|c|}{$3 / 3$} \\
\hline PS (mm) & $1,14 \pm 0,85$ & $0,77 \pm 0,75$ & $1,84 \pm 1,06$ & $0,94 \pm 0,85$ & $1,92 \pm 1,02$ & $0,68 \pm 0,69$ \\
\hline $\mathrm{NI}(\mathrm{mm})$ & $1,13 \pm 0,82$ & $0.77 \pm 0,75$ & $1,85 \pm 1,08$ & $0,94 \pm 0,85$ & $1,95 \pm 1,07$ & $0,72 \pm 0,71$ \\
\hline $\mathrm{IG}$ & 0 & 0 & 1 & 0 & 2 & 0 \\
\hline $\mathrm{IC}$ & 1 & 0 & 2 & 0 & 2 & 0 \\
\hline Sangramento & 16,67 & 0 & 50 & 0 & 66,67 & 0 \\
\hline
\end{tabular}


A produção neutrofílica de superóxido foi maior em todos os estágios da DP, sendo a porcentagem de neutrófilos redutores de NBT. Entretanto, tal diferença em relação ao controle foi significante $(\mathrm{P}<0,05)$ apenas na periodontite leve (Fig. 1).

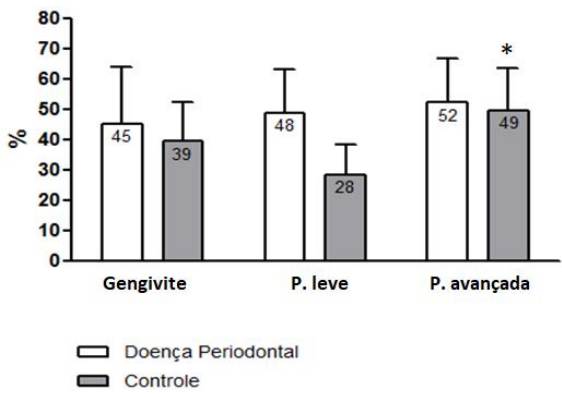

Figura 1. Médias e desvios-padrão da produção de superóxido estimado pela porcentagem $(\%)$ de neutrófilos redutores do tetrazólio nitroazul de cães controle, com gengivite, periodontite leve (P. leve) e avançada (P. avançada). * $\mathrm{P}<0,05$.

A TOC plasmática foi maior apenas nos cães com periodontite, no entanto tal diferença foi significante $(\mathrm{P}<0,05)$ somente na forma avançada desse estágio da DP (Fig. 2).

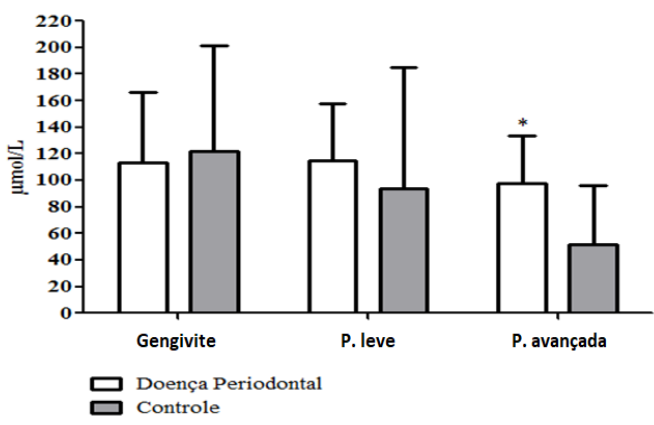

Figura 2. Médias e desvios-padrão da concentração total de oxidantes no plasma de cães controle, com gengivite, periodontite leve (P. leve) e avançada (P. avançada). * $\mathrm{P}<0,05$.
A peroxidação lipídica plasmática estimada pelo TBARS foi menor em $90 \%$ dos cães tratados (controle), porém tal diferença foi significante $(\mathrm{P}<0,05)$ apenas na periodontite avançada

(Fig. 3).

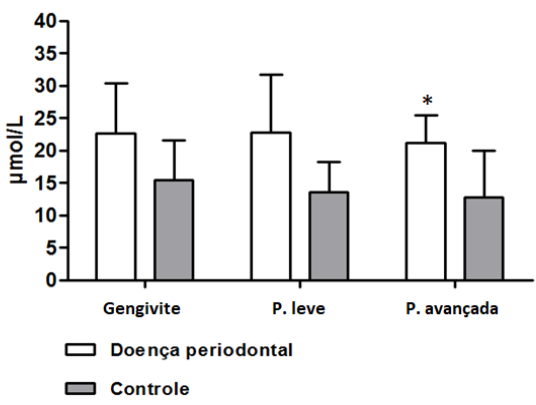

Figura 3. Médias e desvios-padrão da peroxidação lipídica plasmática quantificada pela concentração de substâncias reativas ao ácido tiobarbitúrico em cães controle, com gengivite, periodontite leve (P. leve) e avançada (P. avançada). $* \mathrm{P}<0,05$.

Nenhum dos marcadores de estresse oxidativo da saliva de cães diferiu significativamente $(\mathrm{P}>0,05)$ quanto ao sexo (Tab. 2), e todos apresentaram grande variabilidade (Tab. 3).

A albumina e a TOC do plasma foram maiores que os da saliva, enquanto o ácido úrico e a bilirrubina salivar não diferiram significativamente das concentrações plasmáticas (Tab. 3). Entretanto, não houve correlação significativa $(\mathrm{P}>0,05)$ entre as concentrações salivares e plasmáticas de nenhum dos marcadores de estresse oxidativo mensurado.

Em relação ao controle, os antioxidantes mensurados na saliva (ácido úrico, albumina e bilirrubina) e a TOC salivar não diferiram significativamente (Fig. 4). 
Tabela 2. Médias, desvios-padrão e intervalo de confiança 95\% dos biomarcadores de estresse oxidativo da saliva de cães do grupo controle, conforme o sexo

\begin{tabular}{cccc}
\hline Biomarcadores & Fêmeas & Machos & p-valor \\
\hline Ácido úrico $(\mathrm{mmol} / \mathrm{L})$ & $0,02 \pm 0,01$ & $0,03 \pm 0,02$ & 0,3672 \\
& $(0,01-0,03)$ & $(0,01-0,04)$ & \\
Albumina $(\mathrm{g} / \mathrm{L})$ & $0,74 \pm 0,32$ & $0,75 \pm 0,29$ & 0,6242 \\
& $(0,50-0,99)$ & $(0,54-0,96)$ & \\
Bilirrubina $(\mu \mathrm{mol} / \mathrm{L})$ & $2,40 \pm 2,73$ & $3,48 \pm 3,71$ & 0,8497 \\
& $(0,44-4,34)$ & $(0,84-6,14)$ & \\
TOC $(\mu \mathrm{mol} / \mathrm{L})$ & $7,00 \pm 4,75$ & $14,05 \pm 10,77$ & 0,1736 \\
& $(2,02-11,99)$ & $(2,74-25,36)$ & \\
\hline
\end{tabular}

TOC $=$ concentração oxidante total.

Tabela 3. Médias, desvios-padrão e intervalo de confiança (95\%) dos biomarcadores de estresse oxidativo da saliva e do plasma de cães controle

\begin{tabular}{cccc}
\hline Marcadores de estresse oxidativo & Saliva $(\mathrm{n}=20)$ & Plasma $(\mathrm{n}=20)$ & $\mathrm{p}$-valor \\
\hline Ácido úrico $(\mathrm{mmol} / \mathrm{L})$ & $0,03 \pm 0,03$ & $0,03 \pm 0,02$ & 0,8906 \\
& $(0,02-0,05)$ & $(0,02-0,04)$ & \\
& $0,74 \pm 0,29$ & $32,95 \pm 3,21$ & 0,0001 \\
Albumina $(\mathrm{g} / \mathrm{L})$ & $(0,60-0,89)$ & $(31,40-34,50)$ & \\
& $2,94 \pm 3,22$ & $2,17 \pm 2,16$ & 0,2305 \\
Bilirrubina $(\mu \mathrm{mol} / \mathrm{L})$ & $(1,44-4,45)$ & $(1,16-3,18)$ & \\
TOC $(\mu \mathrm{mol} / \mathrm{L})$ & $10,53 \pm 8,74$ & $91,56 \pm 76,02$ & 0,0025 \\
\hline
\end{tabular}

TOC $=$ concentração oxidante total.
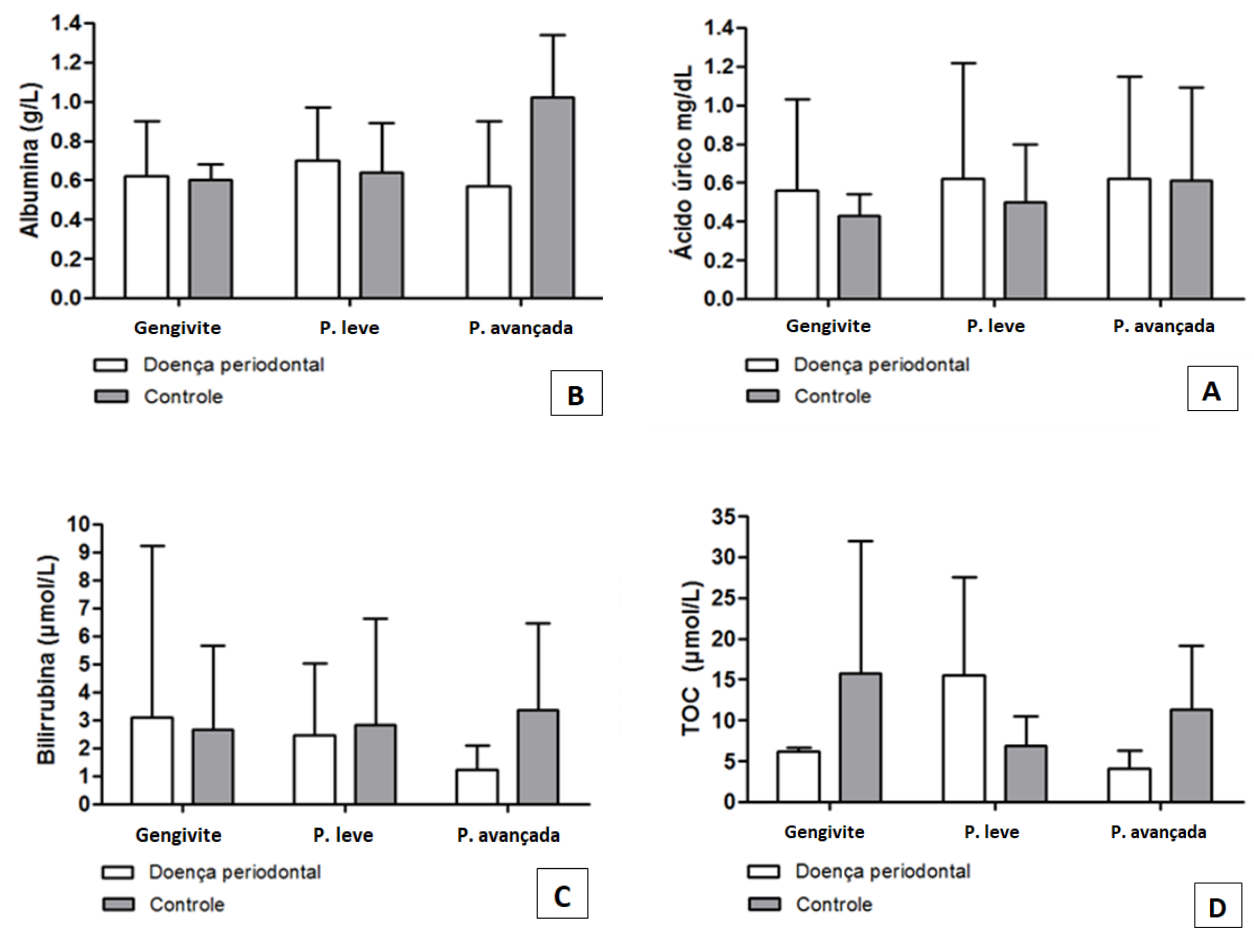

Figura 4. Médias e desvios-padrão dos marcadores de estresse oxidativo salivar: ácido úrico (A), albumina (B), bilirrubina (C) e TOC (D) de cães controles e com gengivite, periodontite leve e avançada. Valores médios e desvios-padrão. 


\section{DISCUSSÃO}

Há relato de que, na periodontite humana, o metabolismo oxidativo dos neutrófilos aumenta (Matthews et al., 2006), entretanto outros não observaram tal alteração (Tapashetti et al., 2013). Esses estudos divergem quanto aos critérios de seleção e classificação dos portadores de DP, sendo esta uma provável explicação para a falta de consenso sobre o papel do metabolismo dos neutrófilos nas doenças periodontais. Nesse sentido, para melhor entendimento do tema, no presente estudo houve a preocupação de avaliar o metabolismo oxidativo dos neutrófilos de cães em três diferentes estágios da DP. Embora tenha sido verificado que a produção neutrofílica de superóxido foi maior em todos os graus da DP canina, tal diferença em relação ao controle foi significante apenas na forma leve da periodontite. Esses resultados indicam que o metabolismo oxidativo dos neutrófilos varia de acordo com o estágio da DP, o que, em parte, pode explicar a falta de consenso dos estudos anteriores realizados em humanos.

Esta é uma das primeiras evidências de que os neutrófilos podem contribuir para EOS, com aumento significativo da produção de oxidantes em pelo menos em um dos estágios da DP dos cães. A presente pesquisa teve a oportunidade de verificar que a progressão do estresse oxidativo em algumas condições causa uma posterior inibição do metabolismo oxidativo dos neutrófilos (Almeida et al., 2013). Portanto, há necessidade de avançar nessa investigação para melhor entender os mecanismo pelos quais o metabolismo oxidativo dos neutrófilos fica mais ativado na periodontite leve dos cães.

O excesso de oxidante tem sido associado ao aumento da peroxidação lipídica plasmática na DP humana (Guentsch et al., 2008), porém, até o momento, não se conhece qual a contribuição do metabolismo oxidativo dos neutrófilos no aumento de TOC e TBARS plasmático nos cães. $\mathrm{O}$ tratamento periodontal utilizado para constituir o grupo controle promoveu uma diminuição significativa na produção neutrofílica de superóxido de cães com periodontite leve, enquanto um declínio significativo de TOC e da peroxidação ocorreu apenas na forma mais avançada da periodontite. Portanto, a confirmação da hipótese de que, em cães, a peroxidação lipídica plasmática nas DP resulta, pelo menos em parte, do aumento do metabolismo oxidativo dos neutrófilos requer outras investigações. Entretanto, os valores significativamente maiores de TOC e TBARS plasmático caracterizam um quadro de estresse oxidativo sistêmico ainda não descrito na periodontite avançada dos cães.

Devido à facilidade de obtenção e a seu contato direto com as lesões bucais, a saliva tem sido utilizada para avaliar o estresse oxidativo de DP em humanos (Miricescu et al., 2011), sendo a composição salivar variável conforme o sexo (Sculley e Langley-Evans, 2003) e a forma de coleta (Nagler et al., 2002). Embora a DP afete a maioria dos cães (Riggio et al., 2011), para fins de comparação, não há registro de outra investigação que tenha quantificado biomarcadores de estresse oxidativo na saliva canina e não se sabe quais os fatores que interferem na composição salivar. Diferentemente do que é relatado em humanos, os biomarcadores salivares avaliados não diferiram quanto ao sexo em cães.

A concentração de albumina na saliva de cães é muito menor do que a do plasma. Já as concentrações de ácido úrico e de bilirrubina salivar foram similares às do plasma, porém não apresentaram correlação entre si. Essa ausência de correlação sugere que, em cães, a síntese e ou o consumo desses biomarcadores diferem nesses dois fluidos.

Estudos em humanos com DP tem utilizado o ácido úrico e a albumina salivar como marcadores de estresse oxidativo (Sculley e Langley-Evans, 2003; Miricescu et al., 2011). O ácido úrico - não a albumina salivar - aumenta de acordo com o grau da DP em humanos (Sculley e Langley-Evans, 2003). Ao contrário, uma diminuição de ambos os antioxidantes na saliva foi descrita na DP humana (Miricescu et al. (2011). Até o momento, papel antioxidante da bilirrubina salivar na DP é desconhecida. Embora os resultados desses estudos sejam contraditórios, há consenso sobre a importância da análise dos antioxidantes na saliva para melhor avaliar o estresse oxidativo da DP.

Os antioxidantes na saliva de humanos variam de acordo com o estímulo empregado para obtenção da amostra salivar (Nagler et al., 2002), com o sexo e a contaminação da amostra com sangue 
(Sculley e Langley-Evans, 2003). No presente estudo, os cães responderam de modo bastante variado a um mesmo estímulo empregado para induzir a salivação, não sendo observada diferença significativa quanto ao sexo dos marcadores de estresse oxidativo na saliva.

É provável que a TOC plasmática seja maior que a salivar em cães controle em razão de o plasma expressar a produção de oxidantes de todos os tecidos corpóreos, enquanto na saliva esse marcador expresse a produção de oxidante do tecido periodontal. Há de se considerar ainda que os oxidantes naturalmente produzidos na cavidade bucal sejam parcialmente neutralizados pelas altas concentrações de antioxidantes presentes na saliva. Os oxidantes são continuamente produzidos nas glândulas salivares e principalmente nos tecidos periodontais lesionados (Lohinai et al., 1998), o que torna a TOC salivar um biomarcador mais sensível para detectar o estresse oxidativo das DP humanas, fato não comprovado no presente estudo.

Essa foi provavelmente a primeira investigação que comprovou ser possível quantificar os principais marcadores de estresse oxidativo na saliva de cães com DP. Entretanto, a análise da saliva não expressou claramente o estresse oxidativo detectado no plasma de cães com DP. Diferentemente de estudos realizado em humanos, a análise da saliva não foi útil para avaliar o estresse oxidativo local na DP canina. É necessário ampliar a investigação, no sentido de padronizar a forma de coleta da saliva, levando em consideração as diferenças raciais e alimentares.

Uma vez evidenciado o estresse oxidativo sistêmico em cães com DP, torna-se necessário aprofundar as investigações, a fim de de melhor entender seus mecanismos e prováveis complicações clínicas decorrentes desse desequilíbrio entre oxidante e antioxidante. Os resultados obtidos são um alerta para que os clínicos veterinários valorizem mais a saúde oral, evitando, dessa maneira, as complicações que potencialmente podem ser ocasionadas pelo estresse oxidativo sistêmico da DP.

\section{CONCLUSÃO}

Há evidências de que a ativação do metabolismo oxidativo dos neutrófilos circulantes contribua para o estresse oxidativo sistêmico na DP canina. A quantificação dos principais antioxidantes e oxidantes na saliva não foi capaz de expressar o estresse oxidativo local causado pela DP canina.

\section{AGRADECIMETOS}

À Coordenação de Aperfeiçoamento de Pessoal de Nível Superior (Capes), pela concessão da bolsa de mestrado.

\section{REFERÊNCIAS}

ALMEIDA, B.F.M.; NARCISO, L.G.; BOSCO, A.M.; PEREIRA, P.P. et al. Neutrophil dysfunction varies with the stage of canine visceral leishmaniosis. Vet. Parasitol., v.196, p.6-12, 2013.

BATTINO, M.; FERREIRO, M.S.; GALLARDO, I.; NEWMAN, H.N. et al. The antioxidant capacity of saliva. J. Clin. Periodontol., v.29, p.189-194, 2002.

BEARD, G.B.; BEARD, D.M. Geriatric dentistry. Vet. Clin. N. Am. Small Anim. Pract., v.19, p.49-74, 1989.

BHANSALI, R.S.; YELTIWAR, R.K.; BHAT, K.G. Assessment of peripheral neutrophil functions in patients with localized aggressive periodontitis in the Indian population. J. Indian Soc. Periodontol., v.17, p.731, 2013.

BOSCO, A.M.; COUTO, R.; PEREIRA, P.P.; ALMEIDA, B.F.M. et al. Clinical value of nitroblue tetrazolium test (NBT) in the diagnosis of canine inflammatory processes. Ars Vet., v.28, p.161-168, 2012.

CANAKCI, V.; YILDIRIM, A.; CANAKCI, C.F.; ELTAS, A. et al. Total antioxidant capacity and antioxidant enzymes in serum, saliva, and gingival crevicular fluid of preeclamptic women with and without periodontal disease. J. Periodontol., v.78, p.1602-1611, 2007.

CORRÊA, H.L.; VENTURINI, M.; GIOSO, M. Cálculo dentário subgengival. Clin. Vet., v.3, p.23-26, 1998.

DALAI, C.; IGNAT-ROMANUL, I.; ROŞCA, E.; MUREŞAN, M. et al. Correlation between histopathological aspects of periodontitis and biochemical changes of oxidative stress. Rom. J. Morphol. Embryol., v.54, p.817-822, 2013.

EREL, O. A new automated colorimetric method for measuring total oxidant status. Clin. Biochem., v.38, p.1103-1111, 2005. 
GUENTSCH, A.; PRESHAW, P.M.; BREMERSTRECK, S.; KLINGER, G. et al. Sigusch Lipid peroxidation and antioxidant activity in saliva of periodontitis patients: effect of smoking and periodontal treatment. Clin. Oral Investig., v.12, p.345-352, 2008.

HARVEY, C.E.; EMILY, P.P. Small animal dentistry. In: HARVEY, C.E.; EMILY, P.P. Periodontal disease. St. Louis: Mosby, 1993. cap.4, p.89-144.

HUNTER, M.I.S.; NLEMADIM, B.C.; DAVIDSON, D.L.W. Lipid peroxidation products and antioxidant proteins in plasma and cerebrospinal fluid from multiple sclerosis patients. Neurochem. Res., v.10, p.1645-1652, 1985

KONUGANTI, K.; SESHAN, H.; ZOPE, S.; SILVIA, W.D. A comparative evaluation of whole blood total antioxidant capacity using a novel nitrobluetetrazolium reduction test in patients with periodontitis and healthy subjects: a randomized, controlled trial. J. Indian Soc. Periodontol., v.16, p.620, 2012.

LIMA, V.M.F.; GONÇALVES, M.E.; IKEDA, F.A.; LUVIZOTTO, M.C.R. et al. Anti-leishmania antibodies in cerebrospinal fluid from dogs with visceral leishmaniasis. Braz. J. Med. Biol. Res., v.36, p.485-489, 2003.

LOHINAI, Z.; BENEDEK, P.; FEHÉR, E.; GYÖRFI, A. et al. Protective efects of mercaptoethylguanidine, a selective inhibitor of inducible nitric oxide synthase, in ligature-induced periodontitis in the rat. $B r . J$. Pharmacol., v.123, p.353-360 1998.

MATTHEWS, J.B.; WRIGHT, H.J.; ROBERTS, A.; COOPER, P.R. et al. Hyperactivity and reactivity of peripheral blood neutrophils in chronic periodontitis. Clin. Exp. Immunol., v.147, p.255-264, 2006.

MIRICESCU, D.; GREABU, M.; TOTAN, A.; DIDILESCU, A. et al. The antioxidant potential of saliva: clinical significance in oral diseases. Ther. Pharmacol. Clin. Toxicol., v.15, p.139-143, 2011.

MIRICESCU, D.; TOTAN, A.; CALENIC, B.; MOCANU, B.; DIDILESCU, A.; MOHORA, M.; SPINU, T.; GREABU, M. Salivary biomarkers: Relationship between oxidative stress and alveolar bone loss in chronic periodontitis. Acta Odontologica Scandinavica, v.1, p.42-7, 2014.

MOORE, S.; CALDER, KA.; MILLER, NJ.; RICEEVANS, C.A. et al. Antioxidant activity of saliva and peridontal disease. Free Radic. Res., v.21, p.417-425, 1994.
NAGLER, R.M.; KLEIN, I.; ZARZHEVSKY, N.; DRIGUES, N. et al. Characterization of the differentiated antioxidant profile of human saliva. Free Radic. Biol. Med., v.32, p.268-277, 2002.

NEMEC, A.; VERSTRAETE, F.J.M.; JERIN, A. et al. Periodontal disease, periodontal treatment and systemic nitric oxide in dogs. Res. Vet. Sci., v.94, p.542-544, 2013.

PAVLICA, Z.; PETELIN, N.; NEMEC, A.; ERZEN, D. et al. Mensurement of total antioxidant capacity in gingival crevicular fuid and serum in dogs with periodontal disease. Am. J. Vet. Res., v.65, p.15841588,2004

RIGGIO, M.P.; LENNON, A.; TAYLOR, D.J.; BENNETT, D. Molecular identification of bacteria associated with canine periodontal disease. Vet. Microbiol., v.150, p.394-400, 2011.

SANTOS, N.S.; CARLOS, R.S.A.;ALBUQUERQUE, G.R. Doença periodontal em cães e gatos - revisão de literatura. Rev. Cient. Med. Vet. Pequenos Anim. Anim. Estimação, v.10, p.1-637, 2012.

SCHENKELS， L.C.P.M.; VEERMAN， E.C.I.; AMERONGEN, A.V.N. Biochemical composition of human saliva in relation to other mucosal fluids. Crit. Rev. Oral Biol. Med., v.6, p.161-175,1995.

SCULLEY, D.V.; LANGLEY-EVANS, S.C. Periodontal disease is associated with lower antioxidant capacity in whole saliva and evidence of increased protein oxidation. Clin. Sci., v.105, p.167172, 2003.

TAPASHETTI, R.P.; SHARMA, S.; PATIL, S.R.; GUVVA, S. Potential effect of neutrophil functional disorders on pathogenesis of aggressive periodontitis. J. Contemp. Dent. Pract., v.14, p.387-393, 2013.

THOMAS, B.; MANDANI, S.M.; PRASAD, B.R.; KUMARI, S. Comparative evaluation of serum antioxidant levels in periodontally diseased patients: an interventional study. Contemp. Clin. Dent., v.5, p.340, 2014.

WEI, D.; ZHANG, X.L.; WANG, Y.Z.; YANG, C.X. et al. Lipid peroxidation levels, total oxidant status and superoxide dismutase in serum, saliva and gingival crevicular fluid in chronic periodontitis patients before and after periodontal therapy. Aust. Dent. J., v.55, p.70-78, 2010

ZIMMERMANN, B.G.; WONG, D.T. Salivary mRNA targets for cancer diagnostics. Oral Oncol., v.44, p.425-429, 2008. 